\title{
Letter to the Editor
}

\section{Decline in CD4 counts in HIV patients}

\section{Dear Editor,}

We read with interest the article titled "Rate of decline in CD4 counts in HIV patients not on antiretroviral therapy" by Patrikar et al published in Med J Armed Forces India 2014; 70: 134-138. In the introduction, authors have mentioned that they have attempted to determine the decline in CD4 count in HIV individuals and assessed the effects of time, treatment, initial CD4 count and age on the rate of CD4 cell count decline, but have excluded 24 patients who were already on antiretroviral therapy (ART). It is not clear as to effects of which treatment the authors are referring to. Similarly the effect of age on CD4 cell decline has not been mentioned in the results.

Variability in the rate of decline of CD4 count among individuals has been well discussed by the authors, but it is a well established fact that RNA viral load is a better predictor of rate of loss of CD4 cells at a population level. ${ }^{2}$ The high cost and non availability are the limiting factors and till the time this becomes freely available, only CD4 cell count will continue to decide the management strategies.

We are about to move into an era, where ART would be initiated even at very high CD4 cell counts as it yields better survival benefits. ${ }^{3}$

\section{R E F E R E N C E S}

1. Patrikar S, Basannar DR, Bhatti VK, et al. Rate of decline in CD4 counts in HIV patients not on antiretroviral therapy. Med J Armed Forces India. 2014;70:134-138.

2. Williams BG, Korenromp EL, Gouws E, Dye C. The Rate of Decline of CD4 T-cells in People Infected with HIV. http://arxiv. org/abs/0908.1556.

3. Williams BG. The benefits of early treatment for HIV. Correspondence. AIDS. 2010;24:1787-1797.

\section{Contributed by \\ Col Rajesh Verma \\ Professor \& Senior Advisor, \\ Department of Dermatology, Command Hospital (Southern Command), \\ Pune 411040, India \\ E-mail address: rajeshverma40@yahoo.com}

Available online 16 July 2014

DOI of original article: http://dx.doi.org/10.1016/ j.mjafi.2013.08.005

0377-1237/\$ - see front matter ๑) 2014, Armed Forces Medical Services (AFMS). All rights reserved. http://dx.doi.org/10.1016/j.mjafi.2014.06.012
Dear Editor,

On behalf of the authors, I thank the readers for deep interest and scholarly analysis of the article. In response to raised concern by the authors, my reply is as below:

The introduction do mention about the assessment of decline in CD4 count in HIV individuals with time, treatment, initial CD4 count and age. However, as rightly brought out the 24 patients on ART were excluded and hence the association with treatment not achieved and the word treatment needs to be deleted from introduction. As regards the age of the patient, there was no significant effect of age on the mean decline in CD4 count. We do agree that this statement should have been mentioned in the result section.

We agree to the fact that RNA viral load is a better predictor of rate of loss of CD4 cells at a population level. However, there was no information available on the RNA viral load and the objective of the study was to estimate the decline in CD4 count and assess the variability in CD4 cell count to base our decision rules on the best evidence available from observational studies.
The authors would surely agree that medicine is a continuously evolving science and it may not be sacrosanct that figures of CD4 counts of 350 or even 500 may remain the guiding principle of treatment for all times to come. In such a scenario we may have to resort to documented evolution of fall in CD4 counts in a particular cohort. The Swiss HIV Cohort Study developed rules to guide frequency of CD4 cell count monitoring in HIV infection before starting ART. ${ }^{1}$ When CD4 counts fall below these limits, increased monitoring frequency becomes advisable and these rules offer guidance for efficient CD4 count below particularly in resource-limited settings.

\section{R E F E R E N C E}

1. Buclin T, Telenti A, Perera R, et al. Development and validation of decision rules to guide frequency of monitoring CD4 cell 
count in HIV-1 infection before starting antiretroviral therapy. PLoS One. 2011;6(4):e18578.
DOI of original article: http://dx.doi.org/10.1016/ j.mjafi.2014.06.012

0377-1237/\$ - see front matter

Seema Patrikar Lecturer in Statistics and Demography, Department of Community Medicine, Armed Forces Medical College, Pune 40, India E-mail address: seemapatrikar@yahoo.com
๑) 2014, Armed Forces Medical Services (AFMS). All rights reserved. http://dx.doi.org/10.1016/j.mjafi.2014.06.013

Available online 10 July 2014

\section{Letter to the Editor}

\section{Monitoring of malaria, Japanese encephalitis and filariasis vectors: What to be concerned?}

Dear Editor,

I read with extreme interest the article on "Monitoring of malaria, Japanese encephalitis and filariasis vectors" by Gopalakrishnan et al. published in MJAFI 2014; 70: 129-133 which reported that "targeted interventions are needed to reduce the disease burden and vector activity in the villages adjoining the military station." 1

In fact, it is no doubt that vector control and self-prevention for mosquito bite are important in prevention of mosquito borne infections. In the present report, the vector monitoring is done and can be a good epidemiology data. However, it should be noted that the data on the vector is only a part in consideration for the situation of the diseases among the military staffs. In fact, military staffs can move to other places, far away from the military station. This might be due to the duty or training session. As Taylor et al. noted, "military operations are conducted in a variety of settings", ${ }^{2}$ hence, it is no doubt that the military staffs might have chance to get the infection from the other settings away from the military station. ${ }^{2}$

\section{R E F E R E N C E S}

1. Gopalakrishnan R, Baruah I, Veer V. Monitoring of malaria, Japanese encephalitis and filariasis vectors. MJAFI India. 2014; 70(2):129-133.

2. Taylor SF, Taylor CL. Dengue fever with hemorrhagic features in a special forces soldier. Prehosp Emerg Care. 2006;10(4):494-501.

Viroj Wiwanitkit Wiwanitkit House, Bangkhae, Bangkok 10160, Thailand E-mail address: wviroj@yahoo.com

Available online 10 July 2014

DOI of original article: http://dx.doi.org/10.1016/ j.mjafi.2013.10.014

0377-1237/\$ - see front matter (C) 2014, Armed Forces Medical Services (AFMS). All rights reserved. http://dx.doi.org/10.1016/j.mjafi.2014.06.014

\section{Reply}

Dear Editor,

I would like to thank the reader for his observations on article titled 'Monitoring of malaria, Japanese encephalitis and filariasis vectors'. It is widely accepted that monitoring of disease vectors is an important component in the management of vector borne diseases. In the case of many arboviral diseases prevention of mosquito bites is the only effective method to prevent disease incidence and transmission. The information on the density, diversity and seasonal prevalence of disease vectors assumes great significance in the context of vector borne diseases ${ }^{1}$ and is not merely 'a part in consideration for the diseases among the military staffs'.
Although 'military operations are conducted in a variety of settings' the staff spend a considerable time, especially night hours in the military station. Most of the disease vectors especially malaria, Japanese encephalitis and filariasis vectors bite during the night. The family members of the staff especially children staying within the military stations are also exposed to the bites of disease vectors. The staff and their family members belonging to non-endemic areas will be having low levels of immunity and are thus more vulnerable to malaria and other mosquito borne disease than the native population. ${ }^{2}$ The villages situated around the cantonment areas often serve as the reservoirs for malaria infections 